\title{
Relationship between impaired apoptosis of lymphocytes and distribution of dendritic cells in peripheral blood and synovial fluid of children with juvenile idiopathic arthritis
}

\author{
Elżbieta Smolewska ${ }^{1,2}$, Barbara Cebula ${ }^{3}$, Henryka Brózik ${ }^{2}$ and Jerzy Stańczyk ${ }^{1}$ \\ ${ }^{1}$ Department of Pediatric Cardiology, 2nd Chair of Pediatrics and Cardiology, Medical University of Łódź, Łódź, Poland \\ 2 Rheumatological Clinic for Children, Medical University of Łódź, Łódź, Poland \\ ${ }^{3}$ Department of Hematology, Medical University of Łódź, Łódź, Poland
}

Received: 2008.03.19, Accepted: 2008.06.30, Published online first: 2008.07.29

\begin{abstract}
Introduction: The pathogenesis of juvenile idiopathic arthritis (JIA) is not fully understood. Recently the present authors described disturbed apoptosis of JIA lymphocytes in both peripheral blood (PB) and synovial fluid (SF) as well as an abnormal distribution of blood dendritic cells (BDCs) between the PB and SF in this disease. Possible relationships between these events during the development of JIA process are assessed here.

Materials and Methods: Lymphocyte apoptosis and BDC counts were assessed in the PB and SF of untreated JIA children. Lymphocyte apoptosis was analyzed by the Annexin-V/propydium iodide assay. Total DC (TDC) number was based on the sum of three BDC subpopulations determined using a panel of monoclonal antibodies against BDC antigens (BDCA): myeloid type $1\left(\mathrm{mDC} 1, \mathrm{BDCA}-1^{+} / \mathrm{HLA}_{-} \mathrm{DR}^{+} / \mathrm{CD} 19^{-}\right)$, myeloid type $2\left(\mathrm{mDC} 2, \mathrm{BDCA}-3^{+} / \mathrm{HLA}^{-\mathrm{DR}}{ }^{+} / \mathrm{CD}^{-} 4^{-}\right)$, and plasmacytoid (pDC, BDCA-2 $2^{+} / \mathrm{HLA}-\mathrm{DR}^{+} / \mathrm{CD} 123^{+}$). Cells were enumerated by the flow cytometric "single-platform" method. The concentration of tumor necrosis factor (TNF)- $\alpha$ and the distribution of particular lymphocyte subtypes in both PB and SF were also investigated.

Results: There was significant positive correlation between apoptosis of PB lymphocytes and SF TDC count $(p=0.002)$ as well as SF TNF- $\alpha$ concentration $(p=0.007)$. SF TNF- $\alpha$ levels also correlated with SF TDC count $(p=0.003)$. Moreover, JIA $\mathrm{SF}$ was distinctly enriched with $\mathrm{CD} 4^{+}$and $\mathrm{CD} 8^{+} \mathrm{T}$ lymphocytes and included $\mathrm{CD} 4^{+} / \mathrm{CD} 25^{\text {high }}$ cells as well. There was significant positive correlation between the number of $\mathrm{CD} 4^{+} / \mathrm{CD} 25^{\text {high }}$ cells and SF JIA BDC count $(\mathrm{p}=0.015)$.

Conclusions: These data suggest a possible link between impaired apoptosis of $\mathrm{PB} / \mathrm{SF}$ lymphocytes and increased recruitment of PB BDCs to SF and other elements of the immune system in JIA, including regulatory $\mathrm{CD} 4^{+} / \mathrm{CD} 25^{\text {high }}$ cells.
\end{abstract}

Key words: juvenile idiopathic arthritis, dendritic cells, lymphocytes, apoptosis.

Abbreviations: AI - apoptotic index, Ann-V - Annexin-V, DC - dendritic cell, BDC - blood DC, JIA - juvenile idiopathic arthritis, $\mathrm{mDC} 1$ - myeloid DC type $1, \mathrm{mDC} 2$ - myeloid DC type 2, pDC - plasmacytoid DC, RA - rheumatoid arthritis, SF - synovial fluid, TDCs - total DCs.

Corresponding author: Elżbieta Smolewska, Department of Pediatric Cardiology, Medical University of Lódź, Sporna 36/50, 91-738 Łódź, Poland, tel./fax: +48 42 617-77-00, e-mail: e.smolewska@wp.pl

\section{INTRODUCTION}

The pathogenesis of juvenile idiopathic arthritis (JIA) is still a matter of extensive investigation. Similarly to adult rheumatoid arthritis (RA), autoreactive $\mathrm{T}$ lymphocytes most probably play the key role in the initiation of this inflammatory process $[2,4]$. After contact with antigen-presenting cells (APCs) they become activated and induce the response of $\mathrm{B}$ lympho- cytes and monocytes/macrophages and the secretion of auto-antibodies and several inflammatory cytokines (e.g. tumor necrosis factor (TNF)- $\alpha$ and interleukin (IL)-1, -6, and -8). This in turn stimulates the activation of fibroblasts and chondrocytes and the release of cartilage-degrading enzymes [2, 15, 28].

Our previous studies showed that lymphocytes from peripheral blood and synovial fluid (SF) are characterized by impaired apoptosis [23-25]. We found increased 
spontaneous apoptosis of peripheral blood lymphocytes [23], but the apoptosis of lymphocytes present in JIA SF was significantly inhibited [25]. This phenomenon likely reflects some key events in the pathogenesis of the disease.

Some studies, including our most recent report, suggested that dendritic cells (DCs) can be an important link in the pathogenic chain of JIA $[9,11,14,26]$. DCs are specialized APCs which circulate via the blood to different tissues where, after maturation, they initiate and regulate $\mathrm{T}$ - and $\mathrm{B}-\mathrm{cell}$ responses [12]. Based on specific antigens (blood DC antigens, BDCA-1, -2, and -3), circulating DCs (blood DCs, BDCs) can be divided into three subsets $[8,20]$. These are plasmacytoid BDCA-2 ${ }^{+}$ DCs (pDCs) and two myeloid subsets, mDC1 (BDCA$\left.-1^{+}\right)$and mDC2 (BDCA-3 $\left.3^{+}\right)[6,7,10,20]$. pDCs typically produce interferon (IFN)- $\alpha$ [9]. Moreover, activated pDCs produce IFN- $\gamma$ and TNF- $\alpha[3,9]$ and express Toll-like receptors (TLR)7 and 9 [7]. Both the mDC1 and mDC2 subtypes were shown to release proinflammatory cytokines (e.g. TNF- $\alpha$, IFN-1 $\beta,-6$, and -8) in response to TLR2 and TLR4 stimulation; however $\mathrm{mDC} 1$ cells are much stronger inducers of $\mathrm{T}$-cell proliferation than $\operatorname{mDC} 2$ [7].

Little is known about BDCs in JIA. One report assessed $\mathrm{BDCA}-2^{+} / \mathrm{CD} 123^{+}$and $\mathrm{CD} 11 \mathrm{c}^{+}$DCs in JIA children [9]. Furthermore, we found deficiency in all subtypes of peripheral blood BDCs (pDC, mDC1, mDC2) which was accompanied by SF enrichment with these cells [24]. Circulating BDCs probably migrate to the joints and participate there in the development of an autoimmune response. In the present study we analyzed the potential relationship between impaired apoptosis of lymphocytes and the distribution of DCs in peripheral blood and SF of children with JIA.

\section{MATERIALS AND METHODS}

\section{Patients}

The study was performed with 25 previously untreated children with JIA, including 15 girls and 10 boys (median age: 12.5 years, range: $3-17$ years). The diagnosis was established according to Durban's criteria [21]. Three stages of JIA activity were also distinguished based on clinical and laboratory criteria, namely low activity (joint movement limited without pain or swelling, no extra-articular symptoms, ESR $<20 \mathrm{~mm} / 1 \mathrm{st}-\mathrm{h}, \mathrm{CRP}<10$ $\mathrm{mg} / \mathrm{l}$ ), moderate activity (moderate intensity of arthritis, and/or slight temperature, ESR 20-60 mm/1st-h, CRP 10-30 mg/l), and high activity (morning stiffness, pain and/or swelling of joints, and/or hepatosplenomegaly, fever, rash, and raised values for laboratory tests ESR $>60 \mathrm{~mm} / 1 \mathrm{st}-\mathrm{h}, \mathrm{CRP}>30 \mathrm{mg} / \mathrm{l})$. Moreover, three types of JIA onset were distinguished: polyarticular, oligoarticular, and systemic disease. The study was conducted in accordance with the Helsinki Declaration and was approved by the local ethics committee.

\section{Immunophenotyping}

For BDC assessment, peripheral blood samples $(n=25)$ were collected during routine laboratory investigations. Moreover, BDCs were detected in SF samples $(n=15)$ obtained during therapeutic biopsy in case of joint involvement. Peripheral blood samples were collected on the day of the joint biopsy. Cell immunophenotype was determined using a panel of monoclonal antibodies (MoAbs) directed against BDC-specific antigens: fluorescein isothiocyanate (FITC)-conjugated BDCA-1, BDCA-2, and BDCA-3 (Miltenyi Biotec, Germany), phycoerithrin-conjugated CD14, CD19 (Caltag Laboratories, USA), and CD123 (Miltenyi Biotec, Germany), as well as three-color-conjugated HLA-DR (Caltag Laboratories, USA). Additionally, several lineage-specific antigens, such as CD3, CD4, CD8, CD19, and CD25, were detected for additional discrimination of particular leukocyte subpopulations (Becton Dickinson, USA). The immunophenotype was assessed by four-color flow cytometry (FACScan, Becton-Dickinson, USA) and analyzed with standard emission filters (FL1-FL4).

\section{Assessment of BDC counts}

The number of BDCs was assessed by the "single-platform" method. Fifty $\mu \mathrm{l}$ of whole blood was added directly to TruCOUNT tubes (Becton Dickinson, USA) containing a known number of fluorescent beads. FACS Lysing Solution (Becton Dickinson, USA) was subsequently added to lyse and thereby eliminate interfering red blood cells (the "lyse-no wash" method). Then the respective MoAbs were added to the tubes for detecting the particular DC antigens. In each sample, 100,000 cells were measured. The absolute DC number (cells $/ \mu \mathrm{l})$ was determined by comparing the number of cellular events to bead events, i.e. the number of measured DCs was divided by the number of fluorescence beads and multiplied by the TruCOUNT bead concentration. Results were presented as the number of peripheral blood BDCs or SF BDCs per $\mu$ l.

BDCs were gated from the population of lymphocytes and monocytes based on the side-scatter (SSC) vs. forward-scatter (FSC) distribution. Then three subpopulations of BDCs were discriminated among the HLA$-\mathrm{DR}^{+}$cells from the mononuclear cell gate. These were two myeloid types, mDC1(BDCA- $1^{+} / \mathrm{CD} 19^{-} / \mathrm{HLA}-$ $\left.-\mathrm{DR}^{+}\right)$and $\mathrm{mDC} 2\left(\mathrm{BDCA}^{-}{ }^{+} / \mathrm{CD} 14^{-} / \mathrm{HLA}^{-} \mathrm{DR}^{+}\right)$. The third subpopulation, pDC, was detected based on the BDCA $-2^{+} / \mathrm{CD} 123^{+} / \mathrm{HLA}_{-} \mathrm{DR}{ }^{+}$immunophenotype. The total DC (TDC) count was calculated as the sum of these three BDC subpopulations.

\section{Assessment of apoptosis}

Mononuclear cells were also isolated from heparinized peripheral blood or SF samples to assess apoptosis. The samples were centrifuged in Histopaque1077 (Sigma Diagnostics, USA) density gradient. The 
mixture of blood and Hank's Balanced Salt Solution (HBSS, Biomed, Poland) was layered on top of the Histopaque media in centrifuge tubes and centrifuged for $30 \mathrm{~min}$ at $200 \times \mathrm{g}$. The interphase region containing peripheral blood mononuclear cells was collected and then washed twice in HBSS and RPMI 1640 medium. The cells were then divided and re-suspended in phosphate-buffered saline (PBS, Sigma-Aldrich Chemie $\mathrm{GmbH}$, Germany) for the apoptosis evaluation. Apoptosis was assessed by detection of phosphatidylserine externalization in the cell membrane using the Annexin-V (Ann-V)/propydium iodide (PI) assay. In brief, cells were washed twice with PBS and then resuspended in $100 \mu \mathrm{l}$ of binding buffer containing $2 \mu \mathrm{l}$ of FITC-conjugated Ann-V and $10 \mu \mathrm{g} / \mathrm{ml}$ of PI (Becton Dickinson, USA). The samples were then incubated for $15 \mathrm{~min}$ at room temperature in the dark and fluorescence was measured by flow cytometry. Lymphocytes were gated from the mononuclear cell population based on the SSC vs. FSC distribution. The apoptotic index (AI) was calculated as the percentage of Ann- $\mathrm{V}^{+}$lymphocytes.

\section{Measurement of TNF- $\alpha$ concentration}

The concentration of TNF- $\alpha$ was also measured in both the serum and SF of the JIA children by a standard immunoenzymatic (ELISA) method (R\&D Systems, USA).

\section{Statistics}

For the statistical analysis of the data, non-parametric Mann-Whitney or Wilcoxon pair tests were used for comparison of the results. Correlation between features was evaluated using the Spearman R-test. Comparisons and correlations were considered significant at a p level $<0.05$.

\section{RESULTS}

The characteristics of the examined group of JIA children are shown in Table 1 . The activity of the disease was considered low in 9, moderate in 7 , and high in 9 JIA children. Ten children were found to have oligoarticular, 12 polyarticular, and 3 systemic disease type of onset. Abnormal anti-nuclear antibodies levels were detected in 7 JIA children with oligoarticular and in 1 with systemic disease. Rheumatoid factor-positive was found only in 4 children, all with polyarticular type of onset.

\section{Apoptosis of peripheral blood and SF lymphocytes in JIA}

Apoptosis of peripheral blood lymphocytes was significantly higher than in SF of the JIA children $(\mathrm{p}<0.0001)$; median AI in peripheral blood lymphocytes was $5.9 \%$ (range: $1.2-12.3 \%$ ) and in SF $0.9 \%$ (range: $0.1-3.4 \%$; Fig. 1).
Table 1. Clinical and laboratory characteristics of the children with JIA

\begin{tabular}{lc}
\hline \multicolumn{1}{c}{$\begin{array}{c}\text { Characteristics } \\
\text { of JIA children }\end{array}$} & \multicolumn{1}{c}{$\begin{array}{c}\text { No. of patients }(\%) \\
\text { or median (range) }\end{array}$} \\
\hline $\begin{array}{l}\text { Total number } \\
\text { Gender }\end{array}$ & 25 \\
Age & 15 girls $(60 \%), 10$ boys $(40 \%)$ \\
Activity of the disease & $12.5(3-17)$ years \\
$\quad$ low & $9(36 \%)$ \\
$\quad$ moderate & $7(28 \%)$ \\
$\quad$ high & $9(36 \%)$ \\
Type of onset & \\
$\quad$ systemic disease & $3(12 \%)$ \\
$\quad$ polyarthritis & $12(48 \%)$ \\
$\quad$ oligoarthritis & $10(40 \%)$ \\
Leukocytes $\left(10^{9} / 1\right)$ & $8.5(3.8-22.5)$ \\
Platelets $\left(10^{9} / 1\right)$ & $350.0(210.0-530.0)$ \\
Erythrocyte sedimentation & $22.5(4-90)$ \\
ratio/1st-h & \\
Serum C-reactive protein & $1.9(0.01-12.4)$ \\
(ng/ml) & \\
Rheumatoid factor & 4 patients $(16 \%)$ \\
Antinuclear antibodies & 8 patients $(32 \%)$ \\
\hline
\end{tabular}

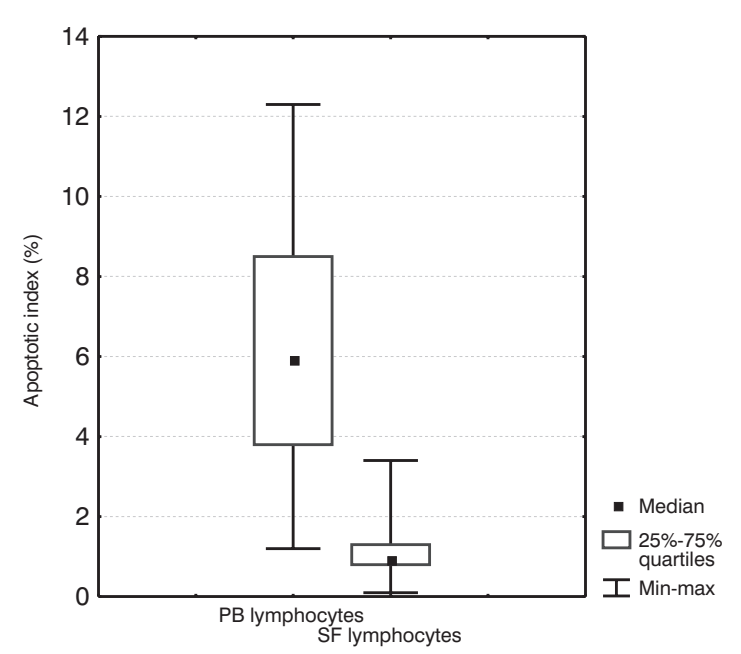

Fig. 1. Differences in apoptosis of peripheral blood (PB) lymphocytes in PB and synovial fluid (SF) from children with JIA.

\section{Differences in the number of BDCs in peripheral blood and SF of the JIA children}

The mean number of TDCs in JIA SF was significantly higher than in the peripheral blood of the JIA children. This concerned TDC count $(p<0.0001)$ as well as all the subtypes mDC1 $(\mathrm{p}<0.0001), \mathrm{mDC} 2$ $(\mathrm{p}<0.0001)$, and $\mathrm{pDC}(\mathrm{p}=0.007$; Table 2$)$.

\section{Correlation between peripheral blood lymphocyte apoptosis and BDC counts in JIA}

The level of spontaneous apoptosis of JIA peripheral blood lymphocytes correlated positively with the 
Table 2. Comparison of the absolute numbers of blood dendritic cells (BDCs) and their subpopulations in peripheral blood (PB) and synovial fluid (SF) of the children with JIA

\begin{tabular}{lcccc}
\hline $\begin{array}{c}\mathrm{BDC} \\
(\text { cells } / \mu \mathrm{l})\end{array}$ & $\begin{array}{c}\mathrm{PB} \\
\mathrm{n}=25\end{array}$ & $\begin{array}{c}\mathrm{SF} \\
\mathrm{n}=15\end{array}$ & p value \\
\hline $\mathrm{TDC}$ & $29.7(9.4-205.6)$ & $602.3(132.6-3565.6)$ & $<0.0001$ \\
$\mathrm{mDC} 1$ & $20.8(5.7-128.0)$ & 246.2 & $(42.1-1761.0)$ & $<0.0001$ \\
$\mathrm{mDC} 2$ & $2.4(0.7-46.6)$ & 151.6 & $(33.8-1305.5)$ & $<0.0001$ \\
$\mathrm{pDC}$ & $6.5(0.7-92.3)$ & 204.5 & $(11.4-2925.5)$ & $=0.007$ \\
\hline
\end{tabular}

TDC - total absolute number of BDCs, mDC - myeloid BDCs, pDC - plasmacytoid BDCs. Medians and ranges are shown.

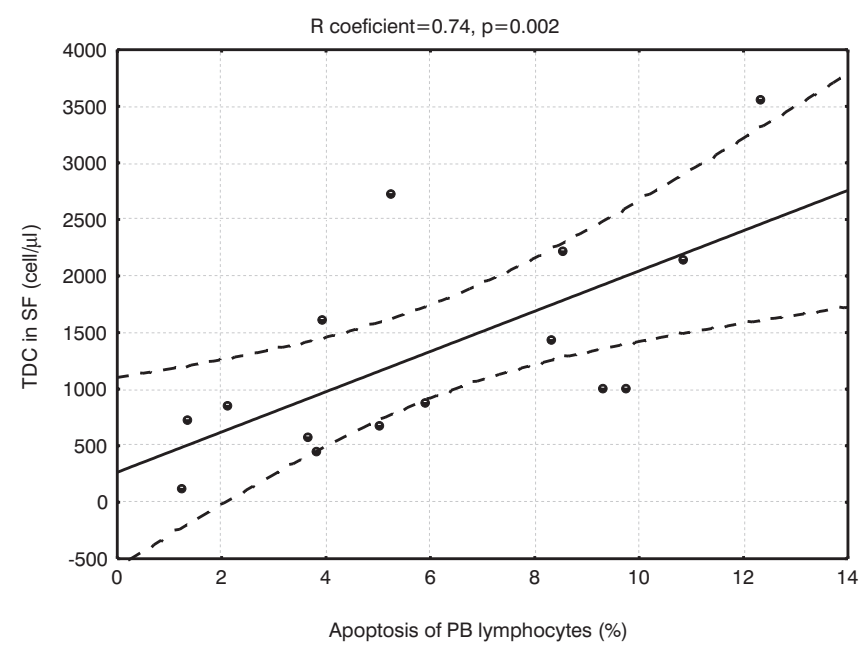

Fig. 2. Correlation between apoptosis of peripheral blood (PB) lymphocytes and the total number of dendritic cells (TDCs) in synovial fluid (SF).

number of TDCs in SF ( $\mathrm{R}=0.74, \mathrm{p}=0.002$; Fig. 2$)$. In contrast, higher peripheral blood lymphocyte apoptosis was associated with more profound depletion of TDCs in JIA peripheral blood; however, this correlation did



Fig. 3. Correlation between lymphocyte apoptosis and the total number of DCs (TDCs) in peripheral blood (PB) in JIA. not reach statistical significance $(\mathrm{R}=-0.35, \mathrm{p}=0.101$; Fig. 3). There was also a distinct tendency towards negative correlation between the rate of SF lymphocyte apoptosis and SF TDC count $(\mathrm{R}=-0.54, \mathrm{p}=0.070$; Fig. 4).

\section{Serum and SF levels of TNF- $\alpha$ in the children with JIA}

Levels of TNF- $\alpha$ in SF were significantly higher than in serum of the JIA children $(\mathrm{p}<0.0001)$. Median TNF- $\alpha$ level in serum was $7.8 \mathrm{pg} / \mathrm{ml}(3.1-82.7 \mathrm{pg} / \mathrm{ml})$ and in SF as high as $199.5 \mathrm{pg} / \mathrm{ml}$ (range: $16.8-376.5 \mathrm{pg} / \mathrm{ml}$; Fig. 5). Spontaneous apoptosis of peripheral blood lymphocytes correlated positively with the level of TNF- $\alpha$ in SF of children with JIA $(R=0.66, p=0.007$; Fig. 6A). Importantly, moreover, SF concentrations of TNF- $\alpha$ correlated significantly with $\mathrm{SF}$ TDC counts $(\mathrm{R}=0.81$, $p=0.003$; Fig. 6B).

\section{Distribution of lymphocytes in peripheral blood and SF JIA compartments}

The absolute numbers of different T-lymphocyte subtypes, including $\mathrm{CD}^{+}$and $\mathrm{CD}^{+}$cells, were higher in SF than in peripheral blood of JIA children $(\mathrm{p}=0.016$ and 0.023, respectively; Table 3). In contrast, CD19+ B-cell counts were significantly lower in SF than in peripheral blood of JIA children $(p=0.006)$. Moreover, a significant prevalence of the population of $\mathrm{CD} 4^{+} / \mathrm{CD} 25^{\text {high }}$ cells was found in JIA SF $(\mathrm{p}=0.026$; Table 3). Interestingly, the number of $\mathrm{SF}$ $\mathrm{CD} 4^{+} / \mathrm{CD} 25^{\text {high }}$ cells correlated with SF TDC count $(\mathrm{R}=0.68, \mathrm{p}=0.015$; Fig. 7$)$. There was no statistically significant correlation between TDC counts and T- or B-cell numbers in SF of the JIA children.



Fig. 4. Correlation between the rate of synovial fluid (SF) lymphocyte apoptosis and the total number of SF DCs (TDCs). 




Fig. 5. Differences in concentration of TNF- $\alpha$ in serum and synovial fluid (SF) from children with JIA.
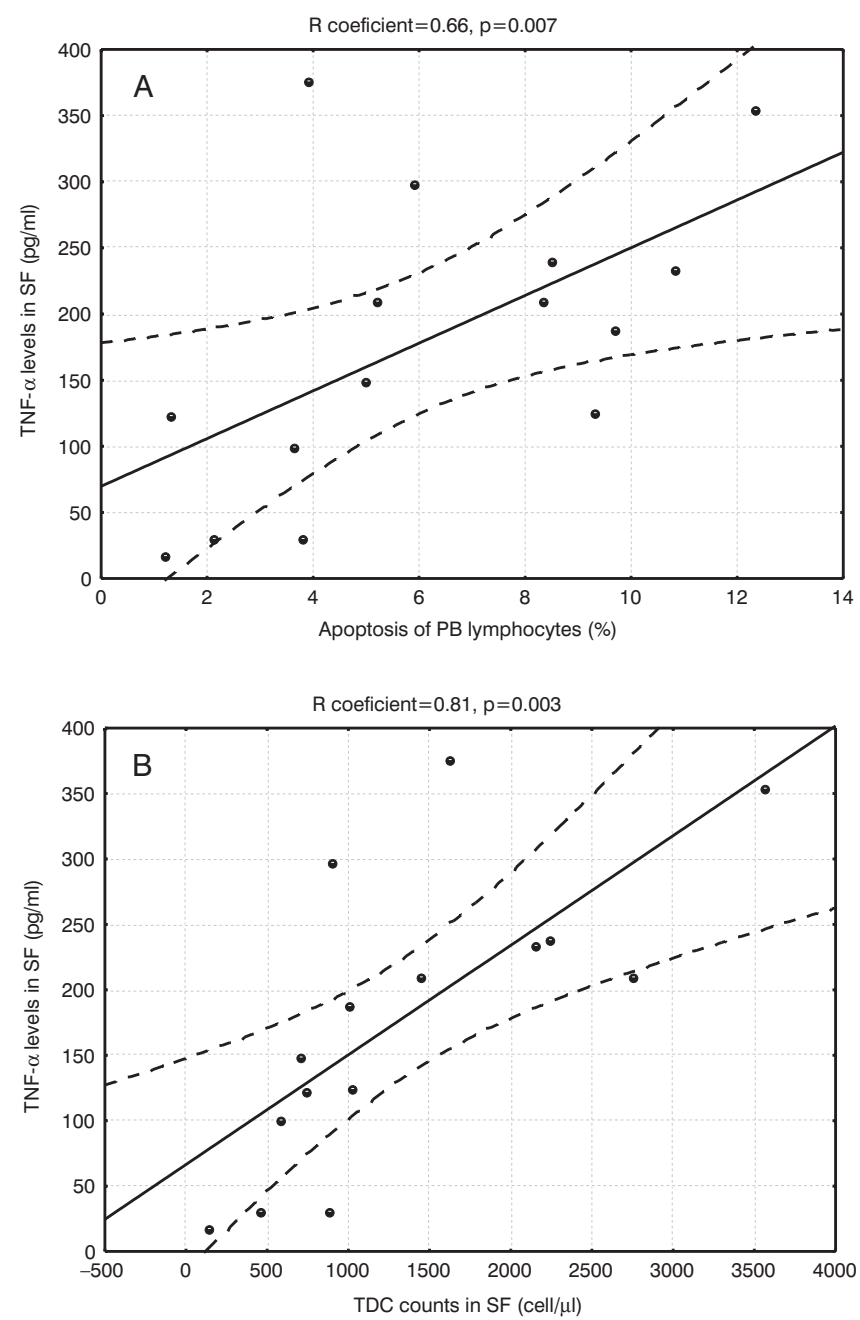

Fig. 6. Correlation between synovial fluid (SF) TNF- $\alpha$ concentration and apoptosis of peripheral blood (PB) lymphocytes or the total number of dendritic cells (TDCs) in children with JIA: A - SF TNF- $\alpha$ concentration vs. PB lymphocytes apoptosis; B - SF TNF$\alpha$ concentration vs. SF TDC counts.
Table 3. Comparison of the absolute numbers of different subpopulations of lymphocytes in peripheral blood (PB) and synovial fluid (SF) of the children with JIA

\begin{tabular}{lccc}
\hline $\begin{array}{l}\text { Cell count } \\
\text { (cell/ } \mu \mathrm{l})\end{array}$ & $\mathrm{PB}$ & $\mathrm{SF}$ & $\mathrm{p}$ value \\
\hline $\mathrm{CD}^{+}$ & 2717.9 & $\mathrm{n}=15$ & \\
& $(1445.1-22056.2)$ & $(3444.3-12085.2)$ & 0.027 \\
$\mathrm{CD}^{+}$ & 1827.8 & 8514.4 & \\
& $(820.4-18501.7)$ & $(2593.7-113213.9)$ & 0.016 \\
$\mathrm{CD}^{+}$ & 1045.0 & 2377.8 & \\
& $(404.4-6827.8)$ & $(858.7-29641.9)$ & 0.023 \\
$\mathrm{CD}^{+}{ }^{+}$ & 61.7 & 540.2 & 0.026 \\
$/ \mathrm{CD} 25^{\text {high }}$ & $(9.7-239.9)$ & $(48.2-3705.2)$ & \\
$\mathrm{CD}^{+} 9^{+}$ & 605.1 & 229.8 & 0.006 \\
& $(147.5-6566.1)$ & $(50.8-2147.5)$ & 0.006 \\
\hline
\end{tabular}

Medians and ranges are shown.

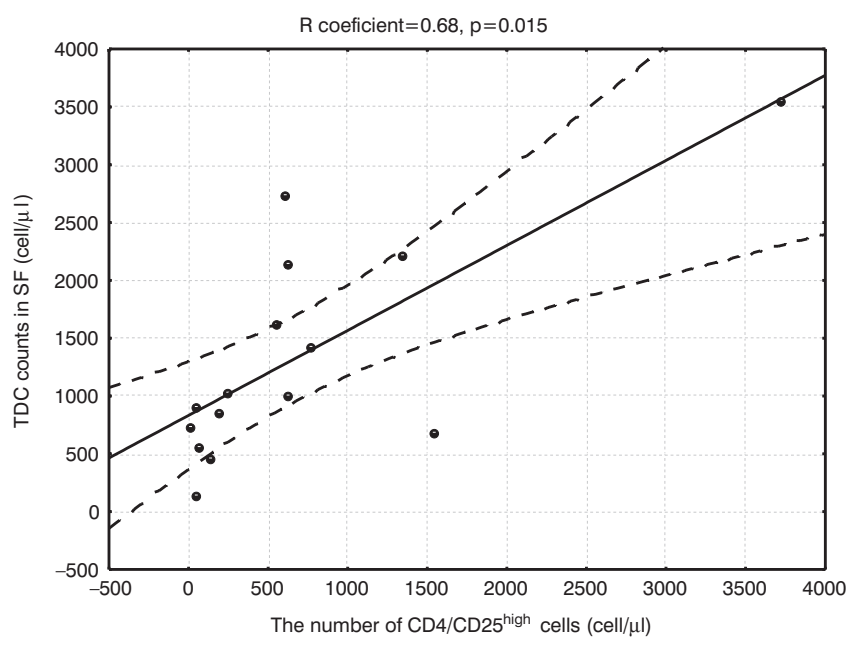

Fig. 7. Correlation between $\mathrm{CD} 4^{+} / \mathrm{CD} 25^{\text {high }}$ cell count and the total number of dendritic cells (TDCs) in synovial fluid (SF) from children with JIA.

\section{DISCUSSION}

In this study we provide for the first time evidence of relationships between abnormalities in impaired lymphocyte apoptosis and disturbed distribution of BDCs in children with JIA. This finding may have an important implication for a better understanding of the pathogenesis of JIA. Previously we showed that apoptosis of peripheral blood JIA lymphocytes is enhanced compared with that of peripheral blood lymphocytes from healthy children [23]. On the other hand, we found that apoptosis of lymphocytes in JIA SF was significantly inhibited in comparison with spontaneous apoptosis occurring in healthy controls $[24,25]$. Very recently we described a deficiency in all subtypes of peripheral blood BDCs in children with JIA and simultaneous enrichment of JIA in these cells, with evidence of their better differentiation and maturation within JIA SF [26].

This study showed significant positive correlation between enhanced apoptosis of lymphocytes in periph- 
eral blood and a high number of BDCs in JIA SF. This suggests an indirect relationship between the activation of apoptosis in circulating lymphocytes and recruitment of BDCs from the peripheral blood to the SF and their accumulation in the latter compartment. It is thus likely that apoptotic bodies containing DNA fragments derived from disintegrating lymphocytes are abstracted by APCs, including BDCs. In turn, BDCs migrate to tissues, including joints and joint-draining lymph nodes, where they mature and may present lymphocytic autoantigens [18], including apoptotic cell-derived DNA fragments [22], and trigger cytokine responses of $\mathrm{T}$ and B cells. This may maintain prolonged autoimmune inflammation with subsequent pannus formation and joint destruction. Our current data provide another argument supporting this thesis, since increased peripheral blood lymphocyte apoptosis significantly correlated with high TNF- $\alpha$ concentration in JIA SF.

We also found significant enrichment of SF with $\mathrm{T}$ cells, predominantly $\mathrm{CD} 4^{+}$lymphocytes. Similar data were previously reported regarding RA $[1,17]$. T cells within the SF of patients with JIA appeared to have a phenotype that would support selective recruitment from the blood [17]. Thus highly differentiated $\mathrm{T}$ cells, which have increased capacity to migrate across inflamed endothelium, may be selectively recruited to the joint. This process itself may alter the expression of activation markers on the cells in the absence of cell proliferation [1]. In the rheumatoid joint enriched with DCs, interaction of DCs and CD4 ${ }^{+}$T cells can therefore be highly augmented. Moreover, IL-15 was found to potently increase the proliferation of T-cell subsets [16]. In light of our previous report [24] showing a highly increased concentration of IL-15 in JIA SF, this may be a possible mechanism promoting SF T-cell expansion in JIA.

Moreover, we observed significant enrichment of JIA SF with $\mathrm{CD}^{+} / \mathrm{CD} 25^{\text {high }}$ cells, considered to be predominantly T-regulatory cells (Tregs). Analysis of FoxP3 mRNA levels revealed a high expression in SF $\mathrm{CD} 4{ }^{+} \mathrm{CD} 25^{\text {bright }} \mathrm{T}$ cells in JIA [5]. Here we showed that high numbers of $\mathrm{CD} 4^{+} / \mathrm{CD} 25^{\text {high }}$ cells corresponded with enlarged numbers of BDCs and strongly suggest an active interaction between these cells in JIA SF. Tregs, enriched in the SF of patients with RA, were found to be capable of suppressing CD4 T-cell proliferation in vitro [15]. In the RA synovium, Tregs might be inhibited by several factors, such as inflammatory cytokines, including TNF- $\alpha$, or stimulated by APCs, such as DCs. This may allow synovial inflammation to evolve and persist despite the enhanced frequencies of synovial Tregs.

In this study we did not assess differences in $\mathrm{CD} 4^{+} / \mathrm{CD} 25^{\text {high }}$ cells between peripheral blood JIA and healthy controls. Wei et al. [27], however, reported a decreased frequency of peripheral blood regulatory $\mathrm{T}$ cells, corresponding to a lower level of CTLA-4 expression on their surface, which may additionally indicate their important role in the immunoregulation of JIA. Similarly, Cao et al. [2] showed significant reduc- tion in $\mathrm{CD} 4^{+} / \mathrm{CD} 25^{\text {high }}$ cells in RA peripheral blood with their enrichment in the joint in RA patients. These data suggest recruitment of regulatory $T$ cells to the joints affected by the JIA or RA inflammatory process.

Interestingly, the absolute numbers of CD19+ cells were significantly lower in SF than in JIA peripheral blood, which was in accord with earlier observations in RA [17]. This might be due to an imbalance between Tand B-cell populations in SF. There is much evidence that $\mathrm{B}$ cells also play an important role in RA development; namely, autoreactive $B$ cells can be driven by $\mathrm{T}$ cells to produce $\operatorname{IgG}$ autoantibodies that may be directly involved in joint damage, and B cells are known to be crucial in activating $\mathrm{CD} 4^{+} \mathrm{T}$ cells [13].

Finally, it is important to mention that all the above data were collected for the first time for JIA by the highly accurate, repeatable, and direct method of cell enumeration by flow cytometry ("single-platform" assay). This method, recently introduced for DC enumeration by Ma et al. [19], seems to be the most reliable for quantitative assessment of different biological phenomena.

In conclusion, spontaneous apoptosis of peripheral blood lymphocytes correlates with enhanced number of BDCs in SF as well SF TNF- $\alpha$ concentration in children with JIA. Simultaneously, JIA SF is significantly enriched with $\mathrm{T}$ lymphocytes, including $\mathrm{CD} 4^{+} / \mathrm{CD} 25^{\text {high }}$ cells. These data support the thesis about a possible pathogenic link between impaired apoptosis of peripheral blood/SF lymphocytes, BDC recruitment to SF, and other key elements of the immune system (e.g. T-cell activation, cytokine production, and impairment of Treg function) in JIA.

\section{REFERENCES}

1. Black A. P., Bhayani H., Ryder C. A., Gardner-Medwin J. M. and Southwood T. R. (2002): T-cell activation without proliferation in juvenile idiopathic arthritis. Arthritis Res., 4, 177-183.

2. Cao D., van Vollenhoven R., Klareskog L., Trollmo C. and Malmström V. (2004): CD25brightCD4+ regulatory T cells are enriched in inflamed joints of patients with chronic rheumatic disease. Arthritis Res. Ther., 6, R335-346.

3. Cavanagh L. L., Boyce A., Smith L., Padmanabha J., Filgueira L., Pietschmann P. and Thomas R. (2005): Rheumatoid arthritis synovium contains plasmacytoid dendritic cells. Arthritis Res. Ther., 7, R230-240.

4. Cope A. P., Schulze-Koops H. and Aringer M. (2007): The central role of $\mathrm{T}$ cells in rheumatoid arthritis. Clin. Exp. Rheumatol., 25, S4-11.

5. de Kleer I. M., Wedderburn L. R., Taams L. S., Patel A., Varsani H., Klein M., de Jager W., Pugayung G., Giannoni F., Rijkers G., Albani S., Kuis W. and Prakken B. (2004): $\mathrm{CD} 4+\mathrm{CD} 25$ bright regulatory $\mathrm{T}$ cells actively regulate inflammation in the joints of patients with the remitting form of juvenile idiopathic arthritis. J. Immunol., 172, 6435-6443.

6. Demedts I. K., Bruselle G. G., Vermaelen K. Y. and Pauwels R. A. (2005): Identification of human pulmonary dendritic cells. Am. J. Respir. Cell. Mol. Biol., 32, 177-184.

7. Demedts I. K., Bracke K. R., Maes T., Joos G. F. and 
Brusselle G. G. (2006): Different roles for human lung dendritic cell subsets in pulmonary immune defense mechanisms. Am. J. Respir. Cell. Mol. Biol., 35, 387-393.

8. Dzionek A., Fuchs A., Schmidt P., Cremer S., Zysk M., Miltenyi S., Buck D. W. and Schmitz J. (2000): BDCA-2, BDCA-3, BDCA-4: three markers for distinct subsets of dendritic cells in human peripheral blood. J. Immunol., 165, 6037-6046.

9. Gattorno M., Chicha L., Gregorio A., Ferlito F., Rossi F., Jarrossay D., Lanzavecchia A., Martini A. and Manz M. G. (2007): Distinct expression pattern of IFN-alpha and TNF-alpha in juvenile idiopathic arthritis synovial tissue. Rheumatology, 46, 657-665.

10. Hackstein H., Renner F.C., Bohnert A., Nockher A., Frommer T., Bein G. and Weimer R. (2005): Dendritic cell deficiency in the blood of kidney transplant patients on long-term immunosuppression: results of a prospective matched-cohort study. Am. J. Transplant., 5, 2945-2963.

11. Harding B. and Knight S. C. (1986): The distribution of dendritic cells in the synovial fluids of patients with arthritis. Clin. Exp. Immunol., 63, 594-600.

12. Hart D. N. (1997): Dendritic cells: unique leucocyte populations which control the primary immune response. Blood, 90, 3245-3287.

13. Kotzin B. L. (2005): The role of B cells in the pathogenesis of rheumatoid arthritis. J. Rheumatol., 73, 14-18.

14. Lande R., Giacomini E., Serafini B., Rosicarelli B., Sebastiani G. D., Minisola G., Tarantino U., Riccieri V., Valesini G. and Coccia E. M. (2004): Characterization and recruitment of plasmacytoid dendritic cells in synovial fluid and tissue of patients with chronic inflammatory arthritis. J. Immunol., 173, 2815-2824.

15. Leipe J., Skapenko A., Lipsky P. E. and Schulze-Koops H. (2005): Regulatory $\mathrm{T}$ cells in rheumatoid arthritis. Arthritis Res. Ther., 7, 93-99.

16. Lin S. J., Wang L. Y., Huang Y. J. and Kuo M. L. (2001): Effect of interleukin (IL)-12 and IL-15 on apoptosis and proliferation of umbilical cord blood mononuclear cells. Bone Marrow Transplant., 28, 439-445.

17. Loza E., Tinturé T. and Sánchez-Ibarrola A. (1999): CD5 and $\mathrm{CD} 23$ expression on $\mathrm{B}$ cells in peripheral blood and synovial fluid of rheumatoid arthritis patients: relationship with interleukin-4, soluble CD23 and tumour necrosis factor alpha levels. Rheumatology, 38, 325-328.

18. Lutzky V., Hannawi S. and Thomas R. (2007): Cells of the synovium in rheumatoid arthritis. Dendritic cells. Arthritis Res. Ther., 9, 219-231.
19. Ma L., Scheers W. and Vandenberghe P. (2004): A flow cytometric method for determination of absolute counts of myeloid precursor dendritic cells in peripheral blood. J. Immunol. Methods, 285, 215-221.

20. MacDonald K. P., Munster D. J., Clark G. J., Dzionek A., Schmitz J. and Hart D. N. (2002): Characterization of human blood dendritic cells subsets. Blood, 100, 4512-4520.

21. Petty R. E., Southwood T. R., Baum J., Bhettay E., Glass D. N., Manners P., Maldonado-Cocco J., Suarez-Almazor M., Orozco-Alcala J. and Prieur A. M. (1998): Revision of the proposed classification criteria for juvenile idiopathic arthritis: Durban, 1997. J. Rheumatol., 25, 1991-1994.

22. Santiago-Schwarz F., Anand P., Liu S. and Carsons S. E. (2001): Dendritic cells (DCs) in rheumatoid arthritis (RA): Progenitor cells and soluble factors contained in ra synovial fluid yield a subset of myeloid des that preferentially activate th1 inflammatory-type responses. J. Immunol., 167, 1758-1768.

23. Smolewska E., Brózik H., Smolewski P., BiernackaZielinska M., Darzynkiewicz Z. and Stanczyk J. (2003): Apoptosis of peripheral blood lymphocytes in patients with juvenile idiopathic arthritis. Ann. Rheum. Dis., 62, 761-763.

24. Smolewska E., Brózik H., Smolewski P., Darzynkiewicz Z. and Stańczyk J. (2004): Regulation of peripheral blood and synovial fluid lymphocyte apoptosis in juvenile idiopathic arthritis. Scand. J. Rheumatol., 33, 7-12.

25. Smolewska E., Stanczyk J., Robak T. and Smolewski P. (2006): Inhibited apoptosis of synovial fluid lymphocytes in children with juvenile idiopathic arthritis is associated with increased expression of myeloid cell leukemia 1 and XIAP proteins. J. Rheumatol., 33, 1684-1690.

26. Smolewska E., Stańczyk J., Brózik H., Biernacka-Zielińska M., Cebula B., Robak T. and Smolewski P. (2008): Distribution and clinical significance of blood dendritic cells (BDC) in children with juvenile idiopathic arthritis. Ann. Rheum. Dis., 67, 762-768.

27. Wei C. M., Lee J. H., Wang L. C., Yang Y. H., Chang L. Y. and Chiang B. L. (2008): Frequency and phenotypic analysis of $\mathrm{CD} 4(+) \mathrm{CD} 25(+)$ regulatory $\mathrm{T}$ cells in children with juvenile idiopathic arthritis. J. Microbiol. Immunol. Infect., 41, 78-87.

28. Yilmaz M., Kendirli S.G., Altintas D., Bingol G. and Antmen B. (2001): Cytokine levels in serum of patients with juvenile rheumatoid arthritis. Clin. Rheumatol., 20, 30-35. 